Eixo Roda, Belo Horizonte, v. 29, n. 3, p. 111-137, 2020

\title{
Carlos Drummond de Andrade e José Osório de Oliveira: a divulgação da poesia drummondiana na revista luso-brasileira Atlântico
}

\section{Carlos Drummond de Andrade and José Osório de Oliveira: The Disclosure of Drummond's Poetry in the Luso-Brazilian Magazine Atlântico}

\author{
Thiago Mio Salla \\ Universidade de São Paulo (USP), São Paulo, São Paulo / Brasil \\ tmsalla@gmail.com
}

http://orcid.org/0000-0001-5009-5157

Resumo: Tomando como objeto os dois poemas publicados por Carlos Drummond de Andrade na revista luso-brasileira Atlântico ("O voo sobre as igrejas" e "Versos à boca da noite"), o presente artigo visa a apresentar estudo sobre os efeitos de sentido produzidos por tal colaboração, considerando a materialidade do veículo em questão e a ambiência discursiva por ele conferida aos textos. Nesse processo, de início, procura-se recuperar as correspondências inéditas enviadas ao poeta mineiro por José Osório de Oliveira, secretário da publicação e reconhecido homem de letras português dedicado à literatura brasileira. Em seguida, apresentam-se a estrutura, as particularidades e as diretrizes da política editorial do periódico, uma espécie de álbum luxuoso considerado o mais importante elo editorial do intercâmbio literário e intelectual pactuado pelas ditaduras de Salazar e Vargas a partir do Acordo Cultural de 1941. Por fim, examina-se o direcionamento interpretativo de ambos os poemas operado pelo suporte, quer no sentido de valorizar uma figura mítica da dita "civilização lusíada", algo caro à proposta de recuperação interessada do passado efetuada pela revista, quer de circunscrever e atenuar o lirismo crítico do autor de Sentimento do mundo.

Palavras-chave: Carlos Drummond de Andrade; José Osório de Oliveira; Atlântico: Revista Luso-Brasileira; Estado Novo brasileiro e português.

Abstract: Considering two poems published by Carlos Drummond de Andrade in the Portuguese-Brazilian magazine Atlântico ("O voo sobre as igrejas" e "Versos à boca da noite"), this article aims to present the results of an investigation into the effects of meaning produced by such collaboration, considering the materiality of the publication in question and the discursive ambience impacting on those texts. Firstly, we seek to recover 
the unpublished letters sent to Drummond by José Osório de Oliveira, secretary of the publication and recognized Portuguese intellectual devoted to the Brazilian literature. Then, the structure and guidelines of the journal's editorial policy are presented. More specifically, Atlântico was a kind of luxurious album which was considered the most important editorial link in the literary and intellectual exchange agreed upon by the Salazar and Vargas dictatorships since the signing of the Cultural Agreement in 1941. Finally, we examine the interpretative framework of both poems operated by the support, which, in the first text, values a mythical figure of the so-called "Portuguese civilization", something dear to the magazine's interested proposal to recover the past, and in the second it intends to circumscribe and attenuate the critical lyricism of the author of Sentimento do mundo.

Keywords: Carlos Drummond de Andrade; José Osório de Oliveira; Atlântico: Revista Luso-Brasileira; Brazilian and Portuguese Estado Novo.

\section{Prolegômenos}

José Osório de Oliveira (Setúbal, 1900 - Lisboa, 1964) foi poeta, crítico literário, ficcionista e ensaísta. Além de atuar como defensor da produção literária realizada pelas então colônias portuguesas na África, trabalhou ativamente para a aproximação entre Portugal e Brasil, escrevendo artigos, proferindo conferências, publicando livros, organizando antologias de autores brasileiros e participando de publicações dedicadas ao intercâmbio cultural entre os dois países. Segundo Mário de Andrade, em crônica publicada no Diário de Notícias do Rio de Janeiro, em agosto de 1940, Osório de Oliveira foi "o primeiro intelectual português a conceber nossa literatura como uma entidade unida e independente, um corpo lógico tradicional em movimento evolutivo, e não apenas como um florilégio de escritores que se sucediam esporadicamente, apenas vivos pelo acaso da maior ou menor inteligência que possuíam" (ANDRADE, 1993, p. 242). E ainda diz Mário que teria sido tal brasilianista o lançador de um mito em Portugal, "a literatura brasileira", e por meio de seu intenso trabalho enquanto crítico teria conseguido transformar esse mito em realidade. Por seu turno, Gilberto Freyre, em referência ao livro História Breve da Literatura Brasileira (1939), base também das considerações elogiosas aqui expressas pelo autor de Macunaíma, afirma que Osório de Oliveira realizou uma "interpretação corajosamente sociológica" e inovadora dos desdobramentos históricos de nossas letras (FREYRE, 1940, p. 2). 
Na continuidade de tal intenso trabalho em prol do intercâmbio literário entre Portugal e Brasil, iniciado em 1926 por Osório de Oliveira, ${ }^{1}$ ele faz publicar, em 1948, o opúsculo Na minha qualidade de luso-brasileiro, no qual reúne algumas páginas de circunstância dedicadas às relações entre os dois referidos países. No livro, destaca-se a transcrição de um discurso pronunciado em jantar oferecido pelo Secretariado da Propaganda Nacional (SPN) em homenagem a Álvaro Lins, em que o crítico português, na defensiva, recupera a iniciativa da revista estadonovista Atlântico (por ele secretariada) no início dos anos 1940 de recrutar escritores brasileiros das mais variadas tendências artísticas e, sobretudo, políticas. Sua atenção, já ao final de sua fala, recai sobre os colaboradores ditos "vermelhos":

[...] como detesto as vagas afirmações, concretizarei dizendo que na Atlântico colaboraram escritores de tendências esquerdistas, como o admirável poeta Carlos D. de Andrade, e até comunistas militantes como o grande prosador Graciliano Ramos e o historiador Caio Prado Júnior, que foi o primeiro a aplicar o materialismo histórico como sistema, ao estudo da formação do Brasil contemporâneo (OLIVEIRA, 1948, p. 29-30).

Mediante tal afirmação, Osório de Oliveira procurava desconstruir a acusação feita por Jorge Amado de que os escritores brasileiros cujos textos foram estampados em Atlântico teriam traído ou desonrado a sua missão. ${ }^{2}$ Não por acaso, ao elencar os colaboradores do periódico situados mais à esquerda no espectro político, o brasilianista visava a legitimar a proposta do veículo que, para além de bandeiras e partidos, teria agregado conservadores, liberais, independentes e até mesmo comunistas, com vistas a um propósito supostamente maior de "união espiritual luso-brasileira". Assim, para Osório de Oliveira, na realização do álbum antológico proposto pela revista, privilegiou-se o que havia de melhor em termos artísticos e intelectuais tanto em Portugal quanto no Brasil, ficando em segundo plano

\footnotetext{
${ }^{1}$ Tal trabalho teria se iniciado com o livro Literatura brasileira (Lisboa; Porto: Lumen), publicado em 1926, o qual contava com prefácio de Carlos Malheiro Dias.

${ }^{2}$ Trata-se de acusação feita pelo romancista baiano na primeira edição brasileira de sua obra Cavaleiro da Esperança (1945), na qual traçou a biografia de Luís Carlos Prestes: "Suicidaram-se alguns quantos escritores nas páginas de Cultura Política ou de Atlântico, na indiferença, no ceticismo, nos DIPS, na forma pela forma, na luta contra a arte social [...]". (AMADO, 2011, p. 13-14).
} 
as tendências e posições político-ideológicas daqueles chamados a colaborar com a publicação.

Quanto à polêmica participação em Atlântico dos escritores brasileiros situados mais à esquerda, ${ }^{3}$ o caso de Graciliano Ramos, que publicou na revista três capítulos de Infância (1945) e o conto "Insônia", já foi oportunamente examinado (SALLA, 2017). Todavia, o mesmo não se pode dizer a respeito de Carlos Drummond de Andrade. No periódico estadonovista, ele estampou dois poemas, um já então publicado em livro e outro aparentemente ainda inédito. Trata-se de "O voo sobre as igrejas" (n. 1, 23 mai. 1942), recolhido em Brejo das Almas (1934), e "Versos à boca da noite" (n. 2, 31 out. 1942), que viria a fazer parte de $A$ rosa do povo (1945). Com o objetivo de remediar tal lacuna, o presente artigo se propõe a investigar os efeitos de sentido produzidos por tais poemas na ambiência discursiva e editorial do periódico, não sem antes recuperar uma parcela ainda inédita das cartas trocadas entre Osório de Oliveira e o poeta mineiro.

\section{Correspondência}

José Osório de Oliveira teve acesso pela primeira vez à obra de Carlos Drummond de Andrade por intermédio do poeta e diplomata brasileiro Ribeiro Couto. Este, em 1932, encaminha um exemplar de Alguma poesia ao brasilianista, que, então, atuava como secretário da revista Descobrimento. ${ }^{4}$ Todavia, essa aproximação inicial mediada por Couto teria demorado cerca de oito anos para resultar em contato direto entre Osório de Oliveira e Drummond. Considerando-se a correspondência passiva do escritor

\footnotetext{
${ }^{3} \mathrm{O}$ termo escritor aqui empregado restringe-se àqueles responsáveis pela produção de textos literários, ou seja, neste caso, Graciliano Ramos e Carlos Drummond de Andrade. Caio Prado Júnior colaborou com a revista Atlântico mediante a publicação do ensaio "Formação dos limites meridionais do Brasil" (p. 36-44), o qual figura no sexto número do periódico, saído em 21 de abril de 1945.

${ }^{4}$ Em carta endereçada a Drummond em 6 de janeiro de 1932, Couto destaca: "Dei um exemplar de Alguma poesia a Georges Readers (115, rue du Dessus des Berges, XIIIe., Paris), outro a Osório de Oliveira, secretário do Descobrimento (17, rua Augusto Rosa, 20 Lisboa) e o terceiro ao grupo da Presença, Olivais, Coimbra, Portugal" (BORTOLOTI, 2019, p. 137). No exemplar enviado a Osório de Oliveira, consta a seguinte dedicatória: "A Osório de Oliveira, em nome do autor. Seu amigo - Ribeiro Couto" (ANDRADE, 1940).
} 
mineiro depositada na Casa de Rui Barbosa, ${ }^{5}$ apenas em 1940 iniciou-se seu intercâmbio missivístico com o colega português.

Na primeira carta remetida por Osório, em 11 de novembro de 1940, este se refere de modo cerimonioso a seu interlocutor como "Exm ${ }^{\circ}$ Senhor Dr. Carlos Drumond (sic) de Andrade, Ilustre Chefe do Gabinete de Sua Excelência o Ministro da Educação e Saúde" (OLIVEIRA, 1940b). Em seguida, pondera que, embora nunca tivesse escrito ao confrade brasileiro e, possivelmente, nunca tivesse lhe enviado um livro de sua autoria, julgava que não seria um desconhecido para Drummond. Para reforçar tal argumento, Osório de Oliveira elenca suas obras devotadas ao Brasil, com destaque para História Breve da Literatura Brasileira (1939), na qual o poeta itabirano recebe uma rápida referência, ${ }^{6} \mathrm{e}$ menciona os amigos que teriam em comum: Mário de Andrade e Cândido Portinari. Por tudo isso, julga que não precisaria de carta de recomendação para realizar o pedido feito por ele logo a seguir, relacionado às consequências da Segunda Guerra:

Vocês, homens felizes que vivem no continente americano, não podem avaliar o que é a situação dos refugiados que das nações da Europa Central se têm vindo acolher em Portugal. O meu país não pode oferecer-lhes senão um refúgio, e essa gente precisa de encontrar uma nova pátria, isto é, um país em que possa ganhar os meios de subsistência e recomeçar a vida. Sei que o Brasil não pode abrir as suas portas a toda gente, mas se alguém, como eu, com a autoridade de amigo do Brasil, disser que conhece uma pessoa digna de ser aí recebida e que nesse país pode ser útil, não servirá isso de alguma coisa? (OLIVEIRA, 1940b, p. 1-2)

Mais especificamente, Osório de Oliveira pedia que o colega brasileiro, valendo-se da condição de chefe de gabinete de Gustavo

\footnotetext{
${ }^{5}$ Conjunto de cartas pertencentes ao Arquivo Carlos Drummond de Andrade que, por sua vez, integra o Arquivo-Museu de Literatura Brasileira pertencente à Fundação Casa de Rui Barbosa. Tal acervo do poeta mineiro reúne documentos por ele acumulados ao longo de sua trajetória pessoal e profissional, cobrindo o período que vai 1917 e 1989. No caso da correspondência pessoal drummondiana, "há 1811 signatários entre nomes consagrados da literatura brasileira e da nossa intelectualidade, poetas da nova geração, escritores estrangeiros, artistas, políticos, amigos, etc." (MINISTÉRIO DA CULTURA, 1998, p. 8). ${ }^{6}$ Trata-se de menção a Alguma poesia, obra que, entre outras responsáveis pela "libertação por meio do modernismo", aceitaria com ironia a realidade física e humana do Brasil (OLIVEIRA, 1939, p. 112-113).
} 
Capanema, intercedesse em favor de uma médica eslovaca, a quem muito considerava e que partira para o Brasil apenas com o permis de transit, e não com o visto de permanência. Vislumbrando possíveis adversidades a serem encontradas por tal senhora, o intelectual português apela ao "sentimento de solidariedade humana" e "à capacidade de simpatia", expressos em Alguma poesia, e conclui: "Tenho a certeza de que não apelo em vão para o poeta e para o homem Carlos Drumond (sic) de Andrade"(OLIVEIRA, 1940b, p. 2).

Pela carta seguinte de Osório, de 2 de dezembro de 1940, depreendese que o poeta mineiro respondera ao apelo que lhe fora feito na missiva anterior, bem como, gentilmente, envia a Osório de Oliveira um exemplar de Sentimento do mundo, ${ }^{7}$ o que leva este a expressar seu fascínio e sua identificação com a poesia do confrade brasileiro: "Não só admirava a sua personalidade poética, como sentia por ela verdadeira atração [...]. Como você, amo as formas nuas, e gosto de esconder sob uma certa secura, uma profunda comoção" (OLIVEIRA, 1940c, p. 1). Em seguida, novamente levando em conta o cargo burocrático exercido por Drummond, torna a lhe fazer uma solicitação, mas dessa vez advoga em causa própria. Depois de escrever o polêmico artigo "Adeus à Literatura Brasileira"8 e ser advertido por Mário de Andrade, ${ }^{9}$ Osório de Oliveira afirma, em tom emotivo, que apenas Drummond poderia concretizar seu anseio de retornar ao Brasil:

\footnotetext{
${ }^{7}$ Tal exemplar, hoje pertencente ao acervo da Biblioteca da Faculdade de Letras da Universidade de Lisboa, continha a seguinte dedicatória: “A José Osório de Oliveira, com a simpatia cordial de Carlos Drummond de Andrade".

${ }^{8}$ Texto estampado inicialmente no Diário de Lisboa, em 16 de junho de 1940, e republicado logo depois na Revista Acadêmica em julho deste mesmo ano. Nele, Osório de Oliveira se questiona: " $[\ldots]$ corresponderão os brasileiros ao interesse que tenho por eles, interessandose igualmente, não digo por mim, mas pela literatura portuguesa?" (OLIVEIRA, 1940a, p. 3). Depois de reconhecer algumas iniciativas brasileiras nesse sentido, salienta que os portugueses faziam mais pelas letras do Brasil, além de viverem naquele momento, "por fatalidade geográfica", a tragédia europeia da Segunda Guerra Mundial, que dificultava a publicação de artigos exclusivamente literários.

${ }^{9}$ Em texto publicado no Diário de Notícias do Rio de Janeiro, em 18 de agosto de 1940, Mário de Andrade surpreende-se desagradavelmente com o tom adotado por Osório Oliveira no referido artigo. Para o crítico brasileiro, seu amigo português "vem irritado com os escritores brasileiros que não lhe mandam seus livros e só por causa disso jura nunca mais escrever sobre a literatura do Brasil. Ora será possível tamanha falta de malícia!" (ANDRADE, 1993, p. 244).
} 
O Brasil é o meu mal; não posso viver com ele, e sem ele vivo uma vida incompleta, só metade da vida. Por isso muitas vezes me revolto contra esse amor que mantém o meu ser dividido. Não receber livros dos brasileiros é como não receber cartas de alguém que amamos; não poder voltar ao Brasil é como estar separado desse alguém. Compreende o meu drama, autêntico drama, de todos os dias e de todas as horas? Por que lhe falo isso? Porque me veio a convicção de que só você pode tornar possível a minha ida ao Brasil neste momento (OLIVEIRA, 1940c, p. 1-2).

Osório de Oliveira demandava do autor de Brejo das Almas um convite formal do Ministério da Educação do Brasil para que ele viesse a nosso país "fazer conferências, ou lições, sobre história comparada das literaturas portuguesa e brasileira, ou qualquer coisa nesse gênero" (OLIVEIRA, 1940c, p. 2). ${ }^{10}$ Tratava-se, segundo o intelectual português, de uma espécie de reconhecimento oficial por parte do governo getulista da utilidade de sua campanha e obra, de longa data, em prol da literatura brasileira. O brasilianista cobrava urgência e externava sua confiança na ajuda de Drummond: "[...] o poeta que intitulou um livro Sentimento do mundo, e que dá, em tantos poemas, tão forte impressão do seu sentimento de solidariedade humana, não pode "ficar insensível a este meu apelo: 'Eu quero o Brasil; eu preciso do Brasil"” (OLIVEIRA, 1940c, p. 2).

Como não obteve resposta, Osório de Oliveira, ansioso, torna a escrever para Drummond a 22 de janeiro de 1941, para saber se o confrade brasileiro teria recebido a solicitação contida em sua última missiva e, ao mesmo tempo, para lhe encaminhar a cópia datilografada de um artigo apologético intitulado "Um Estudo sobre Carlos Drummond de Andrade", prestes a ser por ele publicado na revista lisboeta Ultramar. ${ }^{11}$ Essa nova mensagem parece ter ecoado no vazio, pois nove meses depois, em 8 de outubro do mesmo ano, o intelectual português ainda perguntava ao poeta mineiro se a "mensagem de fraternidade literária" (com o referido ensaio e exemplares do periódico no qual este fora publicado) havia sido recebida. Assim, Osório de Oliveira

\footnotetext{
${ }^{10}$ Além disso pondera que "se entenderem que, por não ter títulos universitários, ou acadêmicos, não estou indicado para professor, [...] poderiam convidar-me para ir aí documentar-me para novo livro sobre o Brasil (o Brasil-país: cidades, paisagens, população, progresso material, cultura social, mesmo aspectos políticos)" (OLIVEIRA, 1940c, p. 2). ${ }^{11}$ cf. OLIVEIRA, 1941a. Texto republicado no Brasil, no suplemento "Autores e Livros" do jornal estadonovista $A$ Manhã, dirigido por Cassiano Ricardo, em 30 de novembro de 1941.
} 
continuava sem saber se sua carta havia sido "captada pela antena que é o [...] 'sentimento do mundo"' de Drummond (OLIVEIRA, 1941b, p. 1). Ao mesmo tempo, não se menciona mais a demanda feita pelo brasilianista a respeito de uma eventual viagem dele ao Brasil. Por seu turno, o autor mineiro parece ter mantido silêncio, e o contato com o colega luso minguou. ${ }^{12}$ Uma nova carta enviada por este exclusivamente àquele, a última que consta do acervo da Casa de Rui Barbosa, data apenas de 16 de fevereiro de $1957 .^{13}$

\section{Fases da Atlântico}

Embora tardio e escasso, o contato entre Osório de Oliveira e Drummond concentrou-se no início dos anos 1940, pois, para além do

${ }^{12}$ Nos anos 1940, tem-se notícia de uma viagem de Osório de Oliveira para o Brasil ocorrida apenas mais de quatro anos depois das cartas enviadas a Drummond, quando o Estado Novo brasileiro já estava prestes a chegar ao fim. Em 6 de julho de 1945, o jornal carioca Correio da Manhã anunciava: "De Lisboa, via Natal, chegou ontem pelo avião da Panair do Brasil, o escritor português José Osório de Oliveira, chefe da Divisão de Propaganda da Agência Geral das Colônias de Portugal" (VIAJANTES, 1945, p. 9). Logo depois, o periódico A Noite destacava que o escritor luso viera ao Brasil a convite do reitor da Universidade de São Paulo para ministrar um curso de extensão universitária de caráter didático, "mas com o cunho marcante de sua própria visão sobre a literatura do Brasil e a literatura de Portugal" (EMBAIXADOR, 1945, p. 3). Em 24 de agosto desse ano, novamente o Correio da Manhã anuncia o início de um ciclo de quatro palestras que o intelectual português faria na sede dos Cursos da Biblioteca Nacional sobre a literatura de seu país (CONFERÊNCIAS, 1945, p. 11). Em 5 de setembro, anuncia-se uma conferência de Osório Oliveira na Faculdade Nacional de Filosofia, intitulada "Novo setor da literatura portuguesa". Em 10 de outubro, noticia-se o regresso, para Portugal, do brasilianista, que ainda teria pronunciado conferências em Porto Alegre e Belo Horizonte. No ano de 1947, tem-se registro de nova estada de José Osório de Oliveira no Brasil: "Partiu ontem com destino ao Rio de Janeiro, a bordo de um clipper da Panair do Brasil o escritor José Osório de Oliveira, que ali tratará dos detalhes dos trabalhos de produção do Leitão Cunha" (A CAMINHO, 1947, p. 3). Depois de trabalhar com esse cineasta português em obra sobre a vida de Castro Alves, teria retornado para Lisboa em novembro de 1947.

${ }^{13}$ Nessa missiva, Osório de Oliveira, depois de assinalar que estava "há muito afastado dos camaradas brasileiros (se por culpa deles ou minha não importa agora considerar)" e de sublinhar que nunca deixou de admirar Drummond como escritor e amigo, solicita ao poeta mineiro o envio de livros e a colaboração deste com o suplemento do lisboeta Diário Ilustrado, cuja direção o brasilianista havia assumido (OLIVEIRA, 1957, p. 1). No topo do documento, Drummond assinala: "Resp. 5.IV.57 / Agradeci. Prometi mandar livros, sem nada para o suplemento, por enquanto. / C." (OLIVEIRA, 1957, p. 1). 
conjunto de cartas aqui brevemente apresentado, devem-se considerar os dois poemas encaminhados pelo poeta brasileiro, em 1942, para serem publicados nos primeiros números da revista Atlântico, periódico secretariado pelo

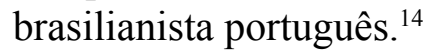

Resultado do Acordo Cultural firmado entre os Estados Novos brasileiro e português em 1941, a revista luso-brasileira Atlântico foi lançada em maio de 1942 com o status de principal instrumento editorial do pacto selado entre as ditaduras salazarista e varguista. Em termos ideológicos, o veículo procurava materializar a chamada "Política Atlântica", uma espécie de pan-lusitanismo, que celebrava os elos entre os países, como se houvesse uma “comunhão espiritual” a irmaná-los. Nas palavras de António Ferro, mandatário do Secretariado da Propaganda Nacional (SPN) e diretor português do periódico, ${ }^{15}$ que nos anos 1920 havia sido celebrado pelos modernistas brasileiros, ${ }^{16}$

\footnotetext{
${ }^{14}$ Não se tem notícia das cartas que trataram do envio dos referidos poemas de Drummond, pois as remessas de textos de autores brasileiros para Portugal eram feitas, sobretudo, entre a seção portuguesa do DIP e a seção brasileira do SPN, ambas criadas em 1942. Além disso, na primeira metade dos anos 1940, convém assinalar que Drummond também figurou em duas diferentes coletâneas organizadas por Osório de Oliveira. No folheto $A$ poesia moderna do Brasil (Coimbra Editora Limitada, 1942), resultado de conferência proferida no Instituto de Estudos Brasileiros da Universidade de Coimbra, em 5 de maio de 1942, ganham espaço "Hino nacional", poema extraído de Brejo das Almas, e três outros oriundos de Sentimento do mundo: "Ode ao cinquentenário do poeta brasileiro", "Menino chorando na noite" e "Os mortos de sobrecasaca". Em 1944, na Pequena antologia da moderna poesia brasileira, obra editada pela referida seção brasileira do SPN, há a presença de apenas um escrito de Drummond: "Lembrança do mundo antigo", texto proveniente de Sentimento do mundo. Textos do autor mineiro ainda viriam a integrar outras duas coletâneas preparadas pelo brasilianista português: Prosas brasileiras (Bertrand, [1949?]) e Líricas brasileiras (Portugália Editora, 1954). Na primeira, tem-se "Vila de utopia", espécie de ensaio publicado inicialmente em Confissões de Minas. Na segunda, novamente "Os mortos de sobrecasaca" e, pela primeira vez, também de Sentimento do mundo, "Os ombros suportam o mundo".

${ }^{15}$ De início, o diretor brasileiro da publicação binacional, de modo análogo, era Lourival Fontes, responsável pelo Departamento de Imprensa e Propaganda (DIP).

${ }^{16}$ Entre os quais se pode incluir Carlos Drummond de Andrade, objeto deste artigo, com o texto "A alma tumultuosa de Antônio Ferro", publicado no Diário de Minas de Belo Horizonte, em 8 de fevereiro de 1923 (apud SARAIVA, 2004, p. 551-553).
} 
Existem duas noções de pátria: a pátria lar que se contém nos limites de suas fronteiras naturais ou artificiais, e a pátria flutuante da raça, difícil, por vezes, de localizar porque se estende por vários mares e continentes. Brasil e Portugal são duas Pátrias inconfundíveis, Pátrias irmãs sem dúvida, com aquele ar de família que não se engana, com profundas afinidades, o mesmo subsolo espiritual, mas cada uma com seu feitio, com suas particularidades. Mas onde se poderia situar a Pátria da Raça comum, a Pátria das duas Pátrias? Resposta fácil. A Pátria das nossas Pátrias, brasileiros e portugueses, é o Atlântico, maravilhoso pomar que o Infante e os seus continuadores semearam de caravelas, cujo mais belo fruto foi o Brasil, palavra sumarenta e luminosa, canto de pássaro ou de fonte (FERRO, 1949, p. 35).

De modo geral, essa ideia de uma nação extraterritorial lusa ou "pátria atlântica flutuante" fundamentava-se menos na geografia (embora o oceano Atlântico figurasse como laço de união) e mais na comunhão de uma mesma matriz lusíada (cultura). Mais especificamente, ancorava-se na herança do passado compartilhado entre uma e outra nação, bem como na noção de uma raça e língua comuns. A princípio, subjaz a tal estratégia de construção de uma comunidade fraterna entre Brasil e Portugal a tentativa de este manter influência cultural sobre aquele, algo que vinha desde o século XIX, mesmo com a independência brasileira (DUTRA, 2005, p. 116). Apesar desse precedente, o fortalecimento dos laços entre nosso país e sua antiga metrópole teria se efetivado, de fato, apenas depois da ascensão de Getúlio Vargas ao poder nos anos 1930, tendo em vista as afinidades entre o nacionalismo autoritário, antiliberal, intervencionista e centralizador dos Estados Novos de lá e de cá (apesar das especificidades de cada um). (GUIMARÃES, 2009, p. 136).

Em conformidade com tais diretrizes, cada número da revista apresentava-se como uma espécie de antologia de Portugal novo aos brasileiros e do novo Brasil aos portugueses (FERRO, 1942). Referindose especificamente a Portugal, o objetivo era mostrar que o país não havia se fossilizado e, por conseguinte, enfatizar a pujança do novo momento português. Quanto ao Brasil, afirmava-se que este gostaria de exportar escritores e artistas "tipicamente brasileiros" e não importar os velhos escritores portugueses do passado. Assim, os dois Estados que se diziam "novos", e, por sua vez, atuavam fortemente na releitura dos tempos idos com o objetivo de construir sua legitimidade no presente, sinalizavam uma 
aparente mudança de perspectiva na relação bilateral até então construída: o intercâmbio passaria a deixar de lado o "teimoso comércio de antiguidades" para se centrar em inquietações e anseios do presente e do futuro (FERRO, 1942).

Ao longo dos oito anos de existência da Atlântico, que circulou entre 1942 e 1950, identificam-se três séries distintas. A primeira delas se estendeu entre 1942 e 1945, totalizando seis volumes, publicados com periodicidade aproximadamente semestral. Seja pelo formato considerado grande $(20,5$ $\mathrm{cm}$ X 27,5 cm), seja pelo número de páginas (em torno de 180), seja pela qualidade superior e pela gramatura do papel, seja pela impressão bem realizada em três cores, pode-se dizer que o periódico apresentava um caráter austero, livresco e luxuoso. Uma parcela considerável dos artigos, poemas e contos contava com ilustrações, fotografias ou reproduções de telas quer coloridas, quer em preto e branco. Não por acaso, o emprego recorrente de imagens corroborava para reforçar a riqueza gráfica do conjunto. Na capa, tem-se uma concha sobre um fundo monocromático e variável, "a sinalizar a isotopia marinha e a comunhão atlântica que governava conceitualmente a realização da revista" (SALLA, 2017, p. 62). Em conformidade com esse mesmo padrão, no miolo, observa-se o emprego de outras imagens/desenhos com motivos marinhos (âncoras, estrelas-do-mar, águas-vivas etc.) para sinalizar, sobretudo, o final dos textos. Conforme destaca um documento oficial pertencente ao acervo do SNI, a tiragem da publicação, nessa fase inicial, seria de 5 mil exemplares (SERRANO, 2009, p. 172).

Cada edição, nessa primeira série da Atlântico, dividia-se em três partes. Na primeira, concentravam-se ensaios de caráter geral e dissertativo, voltados tanto para questões editoriais (tendo em vista a exposição das coordenadas da publicação) quanto históricas e literárias. Na segunda, consagrada à poesia e à novelística, busca-se oferecer ao leitor uma “antologia poética (ordenada por gerações, quando não se imponha a razão da harmonia) e uma escolha de obras de ficção representativas da literatura atual de cada país" (OLIVEIRA, 1942b, p. 170). Mais especificamente,

Quando se observam as produções artísticas publicadas no periódico, percebe-se que a ambiência discursiva a elas fornecida por Atlântico reforçava a dimensão documental de tais textos literários, que de alguma maneira davam a conhecer melhor as especificidades das nações que se irmanavam pela "política atlântica" (SALLA, 2017, p. 62). 
Na terceira e última parte da publicação, ganhavam espaço artigos que privilegiavam informações e análises relativas a acontecimentos e manifestações artísticas contemporâneas ao lançamento da revista. Para além da literatura, destaque, sobretudo, para teatro, música, cinema e artes plásticas, bem como para diferentes figuras pertencentes ao universo cultural luso-brasileiro - escritores, pintores, músicos, atores, entre outros. Tal porção derradeira dos números iniciais de Atlântico abarcava ainda a seção "Notas", redigida por José Osório de Oliveira, "na qual se noticiavam dados diversos da vida intelectual dos dois países e os desdobramentos do acordo firmado entre eles, bem como se realizava de maneira direta o louvor, sobretudo, às realizações do SPN e de seu diretor" (SALLA, 2017, p. 62).

FIGURA 1 - Capa do número de estreia da Atlântico: Revista Luso-Brasileira, datado de 23 de maio de 1942.

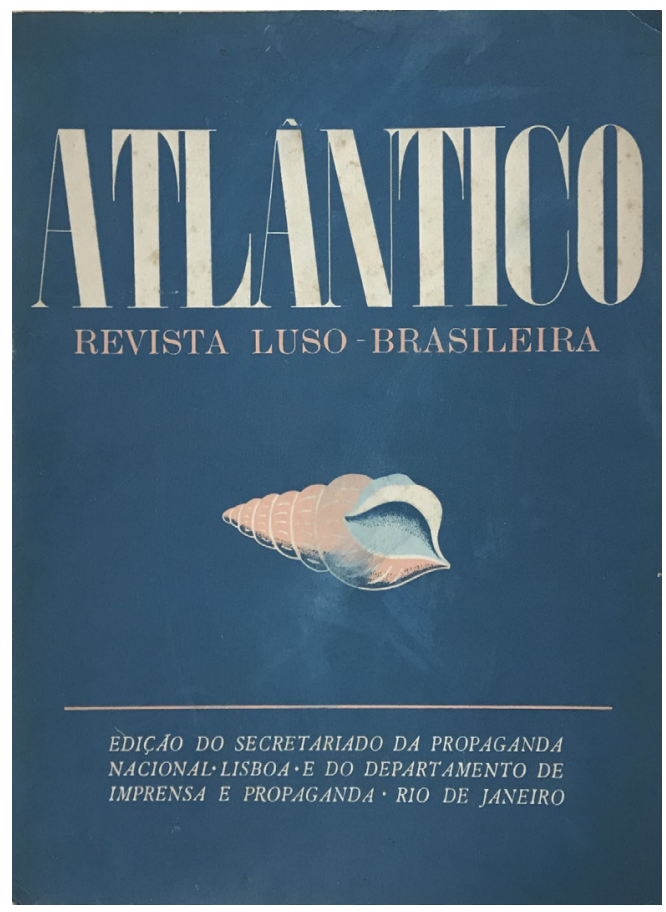

Fonte: Atlântico (1942-1950)

A segunda série de Atlântico restringiu-se ao intervalo 1946-1948, ao passo que a terceira e última abarcou tão somente os anos de 1949 e 1950. 
Nessas novas fases do periódico, observam-se reduções sucessivas em seu formato (que cai para $18,7 \mathrm{~cm} \mathrm{X} 25 \mathrm{~cm}$ e depois para $18 \mathrm{~cm} \mathrm{X} 23 \mathrm{~cm}$ ) e decréscimo na qualidade do papel empregado. Ao mesmo tempo, a impressão deixa de ser feita em três cores, as ilustrações perdem o colorido e caem por terra as subdivisões internas vistas anteriormente. Tais sinais de perda de pujança e organicidade por parte da revista fizeram com que José Osório de Oliveira ressaltasse que o propósito da publicação não seria apresentarse como um álbum luxuoso, mas sim como uma antologia (OLIVEIRA, 1945a, p. 199). Se, a partir de então, Atlântico se mostrava simples, por outro lado se tornava mais frequente e acessível: foram dez números (sete da segunda série e três da última) em cinco anos. O veículo chega ao fim já sem a presença de António Ferro à frente do SPN; o intelectual deixou tal órgão em 1949.

A colaboração de Drummond em Atlântico restringiu-se à fase mais luxuosa da revista, isto é, a primeira. Ao seu lado, outros poetas brasileiros de relevo também fizeram publicar textos em tal veículo: Manuel Bandeira, Vinícius de Morais, Jorge de Lima, Murilo Mendes e Cecília Meireles. Destaque também para os escritos em prosa de Mário de Andrade, Graciliano Ramos, José Lins do Rego, Erico Verissimo, Tristão de Ataíde, Álvaro Lins, entre outros. Considerando-se o rol expressivo de nomes elencados, a intelectualidade nacional parece ter acolhido bem a revista. $\mathrm{O}$ autor de Menino de engenho, por exemplo, dizia que, ao ler Atlâtico, passava a acreditar na possibilidade de se fazer "mais alguma coisa de sério pela aproximação luso-brasileira” (REGO, 1942, p. 4).

\section{Enquadramento da Poesia Drummondiana}

Por mais que Osório de Oliveira insistisse no fato de que Atlântico teria congregado autores de diferentes orientações políticas, incluindo opositores do regime, sabe-se que a publicação exerceu controle sobre a seleção dos colaboradores portugueses para o primeiro número (SALLA, 2017). Além disso, procurou atenuar a imagem hostil de alguns romancistas, sobretudo dos neorrealistas, omitindo não apenas obras ou as denúncias nelas expressas, mas também a própria trajetória de engajamento à esquerda dos escritores em questão. Graciliano Ramos, por exemplo, ganha uma série de atributos positivos (sincero, humano, verdadeiro, inimigo do verbalismo, maduro etc.), mas, obviamente, "em nenhum momento se faz referência à 
dimensão crítica inerente à fatura literária de seus livros e muito menos à sua simpatia pelo PCB, que se transformaria em adesão formal ao partido em 1945" (SALLA, 2017, p. 69).

Logo de saída, curioso observar que nenhum dos dois poemas estampados por Drummond em Atlântico foi extraído de Sentimento do mundo, publicação então mais recente do poeta mineiro. Além disso, tal obra fora referida constantemente por Osório de Oliveira nas cartas por eles trocadas no início dos anos 1940 e, sobretudo, no mencionado artigo de caráter encomiástico "Um Estudo sobre Carlos Drummond de Andrade", publicado inicialmente no primeiro número da revista lisboeta Ultramar, em fevereiro de 1941, republicado no suplemento "Autores e Livros" do jornal estadonovista brasileiro A Manhãa, em novembro deste mesmo ano, e, por fim, recolhido pelo brasilianista no ano seguinte na coletânea livresca Enquanto é possivel. ${ }^{17}$

Nesse último texto, o brasilianista começa por louvar a figura de Gustavo Capanema, "homem para quem as coisas do espírito fazem parte das preocupações do governo" (OLIVEIRA, 1941c, p. 340). Segundo o crítico português, tal juízo seria corroborado sobremaneira pelo fato de o referido homem de Estado ter escolhido como seu principal colaborador o poeta modernista Carlos Drummond de Andrade, artista que, "com perfeita consciência de seus fins", teria colocado em prática o sentido libertador da poética preconizada por Manuel Bandeira (OLIVEIRA, 1941c, p. 340). Em seguida, Osório de Oliveira se põe a fazer uma espécie de resenha de Sentimento do mundo, obra que ressaltaria a "simpatia humana" e a solidariedade do poeta em relação aos outros homens em meio a um contexto militarista. Depois de mencionar "Elegia 1938", poema social marcado por "um acento inconfundível de sinceridade que seria incomum a esse gênero de produção", destaca três textos do referido livro: "Menino chorando na noite" "uma das mais pungentes expressões da imensidade do sofrimento"; "Os mortos de sobrecasaca", "uma das mais patéticas definições daquilo que nas nossas vidas subsiste"; e "Lembrança do mundo antigo", "síntese poética mais lancinante do drama a que estamos assistindo na Europa". (OLIVEIRA, 1941c, p. 341).

${ }^{17}$ Em tal livro, o artigo ganhou o título "Um poeta brasileiro (exemplo de crítica apologética)", que reforça o tom elogioso adotado pelo crítico português (OLIVEIRA, 1942a, p. 141-150). 
Desse modo, quer por salientar tão somente a "sinceridade" num poema no qual avulta a negação da ordem social vigente como "Elegia 1938" - que termina com a sonora confissão do eu lírico (dirigindo-se a si mesmo na segunda pessoa) de que se aceitam certas mazelas do sistema capitalista ("a guerra, o desemprego e a injusta distribuição") devido à impossibilidade de "sozinho, dinamitar a ilha de Manhattan" -, quer por selecionar poemas de caráter lírico cuja alienação seria de ordem temporal, "a separação do passado que entretanto nos formou" (GLEDSON, 1981, p. 118), Osório de Oliveira ou subdimensiona, ou deixa de lado a poesia participante de Sentimento do mundo, preferindo sublinhar o lirismo da obra. Desse modo, não se estranha encontrar tal artigo publicado em uma revista portuguesa situada na órbita do salazarismo. ${ }^{18}$ No entanto, salta aos olhos deparar-se com o mesmo texto republicado no jornal getulista de ampla circulação $A$ Manhã, dirigido por Cassiano Ricardo, considerando não apenas que em 1941, o Brasil ainda matinha uma posição de neutralidade na guerra, mas também o fato de que a primeira edição do livro de Drummond circulara de modo clandestino, pois reunia poemas com posições contrárias às do governo. ${ }^{19}$ Para tanto, vale recuperar o depoimento de Antonio Candido:

De 1940 é o livro Sentimento do mundo, onde a poesia chamada participante ganhou no Brasil uma tonalidade diferente, pois o poeta conseguia exprimir o estado de sua alma de um jeito que importava simultaneamente em negar a ordem social dominante, não faltando poemas nos quais eram visíveis a adesão ao socialismo e a negação do sistema capitalista. Tudo isso em chave de lirismo, como alguma coisa que vem de dentro e existe antes de mais nada enquanto modo de ser; mas revelando tão claramente a posição política incompatível com as funções de chefe de gabinete, que não foi possível lançar o

\footnotetext{
${ }^{18}$ Dirigido pelo jornalista Luiz Figueira, o periódico Ultramar apresentava um longo subtítulo: "revista mensal de assuntos económicos, financeiros e de colonização do Ultramar, de expansão da cultura da raça portuguesa pelo vasto império português, pelo Brasil e terras de além-mar". A publicação teve vida curta; durou apenas seis números, entre fevereiro e agosto de 1941.

${ }^{19}$ Em artigo dedicado ao livro, Vagner Camilo destaca justamente o poema "Elegia 1938", espécie de canto lutuoso ao primeiro aniversário do Estado Novo, no qual, valendo-se de uma "visão desideologizada do esforço", "segue na contramão do empenho estadonovista em consolidar uma ideologia política de valorização do trabalho e de 'reabilitação' do papel e do lugar do trabalhador nacional" (CAMILO, 2002, p. 72-73).
} 
livro no mercado, naquele momento de censura total. Ele saiu numa tiragem fora do comércio, de cento e cinquenta exemplares, que, no entanto, se difundiram razoavelmente por meio de cópias feitas para leitores de empréstimo (CANDIDO, 1993, p. 23-24).

A mesma abertura indireta para a inclusão de alguns poemas de Sentimento do mundo observada em $A$ Manhã, descrita por Luiza Franco Moreira (2001, p. 147) como uma espécie de "cochilo do censor", não se observa em Atlântico, nem mesmo quando se considera o recorte depurado do livro proposto por Osório de Oliveira no artigo examinado anteriormente. Assim, nas páginas da revista luso-brasileira, o problemático caráter transitivo do gauche implicado no espetáculo do mundo (MOURA, 2012, p. 51), com sua poesia política de teor lírico, cede espaço a outras facetas da pena drummondiana, ainda mais quando se considera o enquadramento editorial imposto pela publicação aos textos.

A colaboração de Drummond teve início com "O voo sobre as igrejas", publicado no volume de estreia de Atlântico.$^{20}$ Tal poema, concebido incialmente para um número especial do jornal Estado de Minas, de 29 de agosto de 1930, dedicado ao segundo centenário de nascimento de Antônio Francisco Lisboa, o Aleijadinho (PY, 1980, p. 133), e posteriormente recolhido em Brejo das Almas, encontra-se dividido em quatro seções, nas quais duas possuem verso livre, e duas redondilha maior regular. Os trechos em verso livre apresentam uma procissão de Semana Santa em Ouro Preto que, segundo Gledson (1981, p. 109), transforma-se na descrição do teto da igreja de São Francisco de Assis, pintado por Manuel da Costa Ataíde, ou no teto da própria Igreja de Antonio Dias referida no primeiro verso, de acordo com Vagner Camilo (2000, p. 52). Os trechos em redondilha maior centram-se na figura maior do barroco mineiro: Aleijadinho. Ressaltam-se dois vetores que ainda se fazem presentes na poesia praticada por Drummond nesse momento: modernismo e provincianismo. Sobre este último, recuperação de uma divisão administrativa do Segundo Reinado, ou seja, de antes da proclamação da República, vale perceber que se assinala a ênfase no local e no tradicional, que se coadunam com a perspectiva modernista

\footnotetext{
${ }^{20}$ Ao fim do primeiro número da revista, o poeta é apresentado de modo seco e objetivo ao leitor português: "CARLOS DRUMMOND DE ANDRADE - Nasceu em Itabira (Minas Gerais), em 1902. Poeta, publicou os seguintes livros de poema: 'Alguma poesia', 'Brejo das Almas' e 'Sentimento do mundo'” (COLABORADORES, 1942, p. 178).
} 
de descobrir o Brasil dito verdadeiro. Destaque para Aleijadinho, um dos maiores gênios brasileiros, pois teria produzido um estilo único, renovando e adaptando o "barroco" ao ambiente rude da região das Minas.

Não por acaso, neste número de Atlântico, chamava atenção o ensaio de Mário de Andrade, "O gênio e a obra do Aleijadinho", no qual destacava que nos três séculos de vida colonial esse artista era "o único que se poderá dizer nacional, pela originalidade de suas soluções" (ANDRADE, 1942, p. 30). O ensaio vem acompanhado de duas reproduções fotográficas de páginas inteiras que tornariam mais palpável ao leitor o caráter único e eminentemente brasileiro de Aleijadinho: a frontaria da igreja de São Francisco de Assis de Ouro Preto, que se distinguiria das soluções barrocas luso-coloniais por sua denguice, sensualidade e equilíbrio, e a estátua do profeta Jonas, situada em Congonhas do Campo, marcada pelo misticismo e expressionismo. E, por fim, ainda sublinha: "por outro lado, ele coroa, como gênio maior, o período em que a entidade brasileira age sob a influência de Portugal. É a solução brasileira da Colônia. É o mestiço e é logicamente a independência" (ANDRADE, 1942, p. 30-31). ${ }^{21}$

\footnotetext{
${ }^{21}$ De modo análogo, na crônica "De Vila Rica de Albuquerque a Ouro Preto dos estudantes", ao tratar de Aleijadinho, o poeta Manuel Bandeira destaca-o como um dos maiores gênios brasileiros, pois ele teria produzido um estilo único, renovando e adaptando o "barroco" ao ambiente rude da região das Minas. "Entenda-se que o diminutivo Aleijadinho é significativo da pura compaixão e meiguice brasileiras. O homem a que ele se aplicou nada tinha de fraco nem pequeno. Era em sua disformidade, formidável. Nem no físico, nem no moral, nem na arte, nenhum vestígio de tibieza sentimental. Toda sua obra de arquiteto e de escultor é de uma saúde, de uma robustez, de uma dignidade a que não atingiu nunca nenhum outro artista plástico entre nós" (BANDEIRA, 1937, p. 65-66).
} 
FIGURA 2 - Página do artigo "O gênio e a obra do Aleijadinho", de Mário de Andrade, publicado em Atlântico: Revista Luso-Brasileira e ilustrado com uma fotografia da estátua do profeta Jonas, trabalho de Aleijadinho que se encontra no adro do Santuário do Bom Jesus de Matosinhos, em Congonhas em Congonhas (MG).

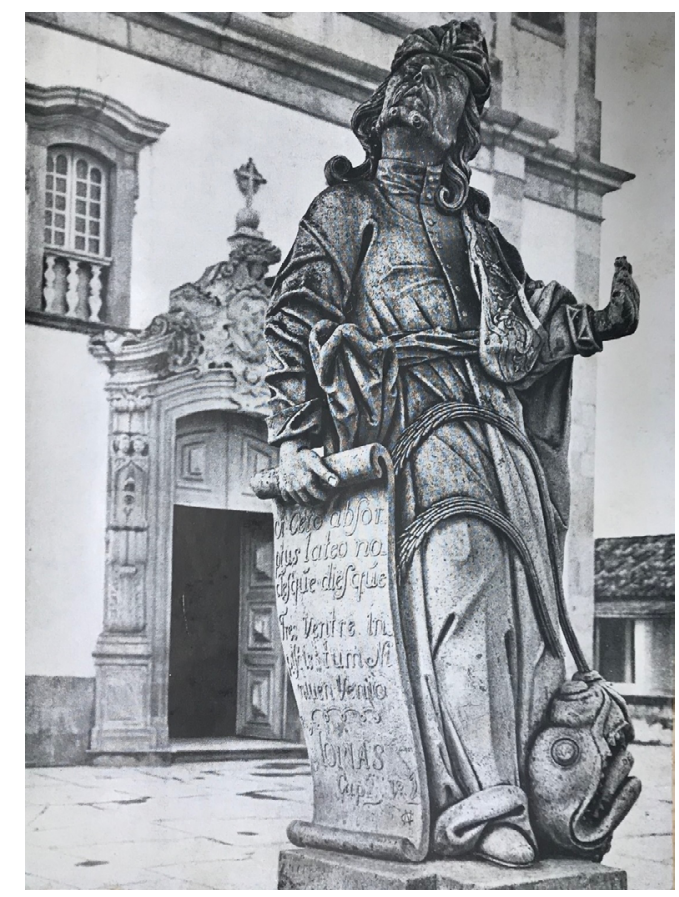

Fonte: Andrade (1942)

Na versão publicada na revista, assim como em Brejo das Almas, fazem-se presentes o ceticismo e a ironia que marcam a produção poética de Drummond (sobretudo na primeira metade dos anos 1930). Todavia, quanto ao final irônico que ressalta a irrealidade de Aleijadinho ("[...] e o Aleijadinho era uma vez"), avultam leituras distintas passíveis de serem privilegiadas por um e outro suporte. Se no livro, segundo Vagner Camilo, tal desfecho assinala o quão distante se mostra o poeta moderno do poder de sublimação da arte encarnado por Aleijadinho, cabendo-lhe apenas ponderar a respeito do lodaçal no qual se encontrava e do qual ansiava sair; na revista, quando se considera o diálogo do poema em questão com o texto de Mário e com a própria diretriz de recuperação do passado levada a termo por Atlântico, Aleijadinho pode ser alçado à condição de mito da 
civilização lusíada, que reafirmaria os laços entre Portugal e Brasil. Em outras palavras, se a retomada do gênio barroco pode ser lida (sobretudo em Brejo das Almas) como estratégia para assinalar o impasse no qual se encontraria o artista moderno, em Atlântico, enquadrar-se-ia na reencenação de um outrora mítico, no qual a "independência" referida por Mário, longe de opor as antigas metrópole e colônia, reforçava, em chave genealógica, a viva confirmação do suposto caráter fecundo da colonização lusa.

FIGURA 3 - Página de abertura do poema "O voo sobre as igrejas", publicado no número de estreia de Atlântico: Revista Luso-Brasileira

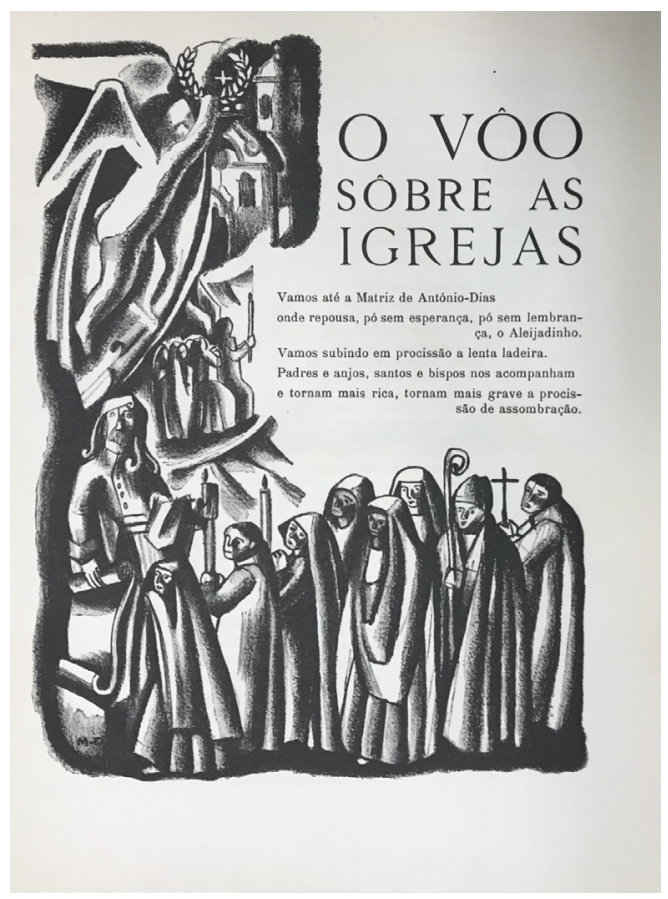

Fonte: Andrade (1942a)

Quanto ao segundo poema de Drummond estampado em Atlântico, "Versos à boca da noite", trata-se de uma meditação sobre o envelhecimento, o princípio do fim, em que avulta "a insatisfação do indivíduo consigo mesmo, a nostalgia de um outro eu que não pode ser, e a perplexidade que leva a explorar o arsenal da memória" (CANDIDO, 1977, p. 99). Tal pensamento, por mais que insinue as agruras do poeta em relação à vida 
presente, não direciona críticas diretas ao contexto imediato de vigência das ditaduras salazarista e getulista (ou mesmo, em chave mais ampla, à Segunda Guerra Mundial). Ao mesmo tempo, a própria ambiência discursiva conferida pela revista ao texto, considerando-se, sobretudo, o discurso do periódico a respeito da "Política Atlântica" e sua proposta antológica, fazia com que nele prevalecessem a beleza e o denso lirismo da poesia drummondiana, digna de figurar na seleta coleção de produções de artistas luso-brasileiros proposta por Atlântico em cada um de seus números. Mais especificamente, se o escrito em questão colocava Drummond ao lado dos grandes autores que escreveram sobre a senectude (ACHCAR, 2000, p. 58), o periódico getulista se apropriava de tais louros na depurada seleta literária binacional proposta.

Ainda em termos de enquadramento editorial, tal poema vem acompanhado da reprodução de uma tela da pintora modernista portuguesa Estrela de Faria (1910-1976), que traz, quase em página inteira, a imagem em preto e branco de um homem calvo de certa idade, com a mão no queixo e o olhar cansado e meditativo, como se visse "tudo impossível e nítido, no espaço" (ANDRADE, 1942b). Estabelece-se, assim, um diálogo direto entre o conteúdo mais imediato do poema, com ênfase na dimensão existencial do texto, e a representação pictórica da artista, de modo a ressaltar o peso do tempo que abatia sua mão pesada sobre o eu lírico, cuja explicação forjada para a própria vida se perdera. ${ }^{22}$

Tal "leitura implícita", decorrente da apresentação da matéria tipográfica e do discurso veiculado pela publicação estadonovista, colocava em segundo plano a dimensão social presumida pelo texto. A consciência do ser a respeito do tempo pressupõe a consciência da destruição da vida, do desgaste contínuo e progressivo que se abate sobre ela e, por sua vez, sobre o corpo do próprio poeta (SANT'ANNA, 1972, p. 145-151). Nesse sentido a percepção aguda do presente que brota em Sentimento do mundo e se intensifica em $A$ rosa do povo pode ser vista como uma forma de luta,

\footnotetext{
${ }^{22}$ Provavelmente Drummond já conhecia o trabalho de Estrela Faria (ou já teria ouvido falar dela), uma vez que Manuel Bandeira, em crônica de dezembro de 1941 publicada no jornal governista $A$ Manhã , celebra a sutileza e a ternura do traço da pintora, que juntamente com Almada Negreiros e Carlos Botelho, entre outros, teve trabalhos apresentados na exposição de desenhos de artistas portugueses então realizada na ABI, sob a iniciativa do Secretariado da Propaganda Nacional, dirigido por António Ferro (BANDEIRA, 2008, p. 280-281).
} 
ou mesmo como um contrapeso, diante da morte reinante, tendo em vista o contexto trágico do mundo em plena guerra mundial. No suporte livresco, por outro lado, justaposto a outros poemas mais engajados, mostra-se mais difícil apartar a perspectiva de dissipação da vida contida em "Versos à boca da noite" do panorama imediato e dramático de enunciação do poeta, cuja percepção mais ampla do todo fora "comprada em sal, em rugas e cabelo" (DRUMMOND, 1942b).

FIGURA 4 - Página do poema "Versos à boca da noite" publicado em Atlântico: Revista Luso-Brasileira, que conta com a reprodução de um quadro da pintora Estrela de Faria.

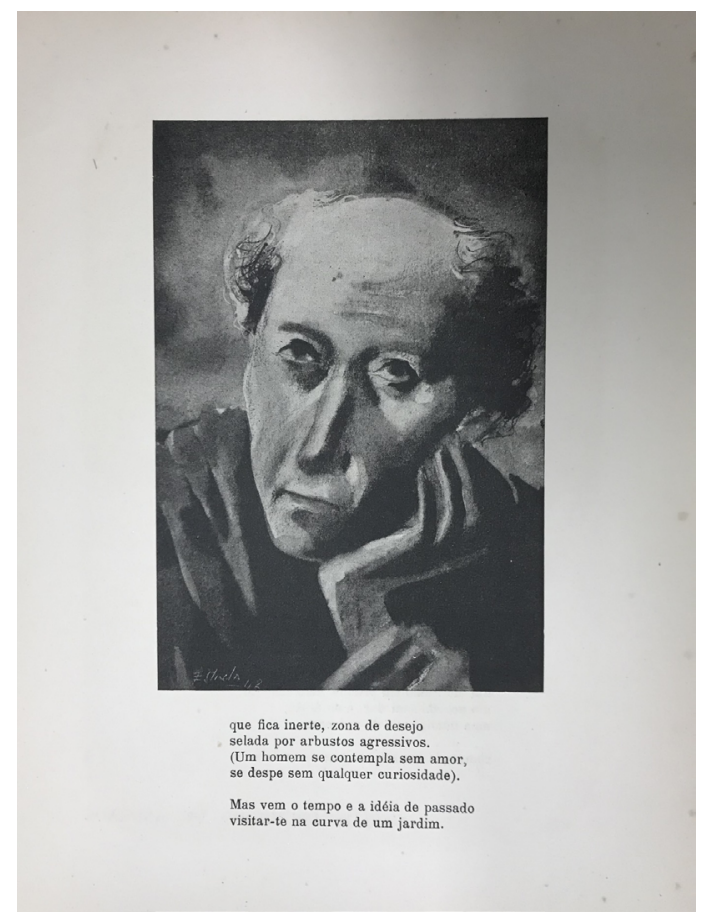

Fonte: Andrade (1942b)

Ao mesmo tempo, convém assinalar que "Versos à Boca da Noite" estava distante de "Nosso tempo" e "Carta a Stalingrado, poemas emblemáticos de Drummond, marcados explicitamente pelo engajamento social que, assim como o texto em questão, viriam a compor $A$ rosa do povo. Para não adotar apenas uma perspectiva projetiva (uma vez que esta 
última obra alcança os leitores apenas em 1945), "Versos à Boca da Noite" também se mostrava afastado, por exemplo, de "A noite dissolve os homens", texto de Sentimento do mundo, no qual toma lugar, já no título, a imagem da noite, porém mais diretamente associada, em termos metafóricos, ao sombrio momento presente de ascensão de regimes ditatoriais e de combates nas ruas, algo coletivamente partilhado por todos, ao qual se contraporia a Aurora responsável por expulsar a treva noturna: "O triste mundo fascista se decompõe ao contato de teus dedos" (ANDRADE, 1967, p. 113). ${ }^{23}$

\section{4 À guisa de uma conclusão}

Diferentemente do diálogo intelectual longevo e duradouro que se observa entre Osório de Oliveira e, por exemplo, Mário de Andrade, ${ }^{24}$ o contato entre o brasilianista português e o poeta Carlos Drummond de Andrade concentrou-se no início da década de 1940 e desdobrou-se na publicação de apenas dois poemas do autor mineiro em Atlântico. Na revista secretariada pelo brasilianista, o enquadramento discursivo-editorial imposto a tais textos fazia com que, de modo análogo ao observado com os quadros de infância de Graciliano Ramos também publicados no periódico (SALLA, 2017), os impasses presentes na poesia de Drummond fossem amainados e/ ou descolados do momento de enunciação do veículo estadonovista. Mais especificamente, quer pela escolha dos poemas realizada pelo periódico, quer pelo direcionamento interpretativo daqueles nas páginas deste, prevalece a orientação de leitura no sentido de ressaltar a mitificação de Aleijadinho,

\footnotetext{
${ }^{23}$ Antes de ser recolhido no livro Sentimento do mundo, tal poema havia sido publicado inicialmente na revista de orientação comunista Esfera: Revista de Letras, Artes e Ciências, em julho de 1938 (GLEDSON, 1981, p. 301).

${ }^{24}$ Osório de Oliveira se correspondeu com Mário de Andrade por quase vinte anos: de agosto de 1923 até março de 1943. Em Atlântico, além do já referido artigo "O gênio e a obra do Aleijadinho", presente no número de estreia da revista, o escritor paulista teve ainda outros artigos, além de trechos de poemas e cartas publicados no periódico. Além disso, o brasilianista, nos textos de sua autoria, constantemente se referia elogiosamente ao autor de Macunaima, bem como prestou a ele singela homenagem, quando da morte do amigo ocorrida em 25 de fevereiro de 1945 (OLIVEIRA, 1945b, p. 183). Ele chega a afirmar, em carta ao próprio Mário, datada de outubro de 1943: "Só se fosse de todo impossível, não daria, nessa revista luso-brasileira, todo o lugar a Mário de Andrade" (OLIVEIRA apud SARAIVA, 2004, p. 457).
} 
personagem valorada pelo discurso oficial ("O voo sobre as igrejas"), e de reduzir o questionamento presente no embate entre a própria subjetividade do poeta (lirismo individualista) e um premente lirismo de caráter social e político ("Versos à boca da noite").

Desse modo, diferentemente de certas críticas feitas no período pós-Segunda Guerra Mundial a intelectuais que colaboraram com o Estado Novo, Drummond não teria se suicidado nas páginas de Atlântico (AMADO, 2011, p. 13-14). ${ }^{25}$ Muito pelo contrário, ele não teria alienado sua pena ao colaborar com a revista oficial, do mesmo modo que, em sentido mais amplo, ao trabalhar como chefe de gabinete de Capanema, apenas servira o governo em questão sem comprometer "a menor parcela de sua dignidade ou autonomia mental (CANDIDO, 2001, p. 74). Por outro lado, ao se considerar a materialidade do periódico aqui analisado e, mais especificamente, a ambiência discursiva por ele conferida às diferentes colaborações, os dois poemas não só abrilhantaram o luxuoso álbum luso-brasileiro proposto pela publicação, como a leitura de ambos, levando-se em conta sobretudo as diretrizes preconizadas pela dita "Política Atlântica", acaba sendo orientada no sentido de reforçar os elos entre as ditaduras varguista e salazarista, ciosas por recuperar e disciplinar, como estratégia de legitimação, a suposta "unidade espiritual" entre Brasil e Portugal.

\section{Referências}

A CAMINHO do Rio o escritor José Osório de Oliveira. A Noite, Rio de Janeiro, 31 jul. 1947, p. 3.

ACHCAR, Francisco. Carlos Drummond de Andrade. São Paulo: Publifolha, 2000 .

AMADO, Jorge. Cavaleiro da esperança. São Paulo: Companhia das Letras, 2011.

ANDRADE, Carlos Drummond de. Sentimento do Mundo. Rio de Janeiro: Pongetti, 1940. Exemplar pertencente a José Osório de Oliveira que faz parte

\footnotetext{
${ }^{25}$ Em tal cenário, Drummond figurou como alvo preferencial, sobretudo, de comunistas. Destaque para o rumoroso artigo "Intelectuais que traíram o povo", publicado por Oswaldo Peralva na revista carioca Para Todos, em março de 1951, no qual, entre inúmeros ataques, refere-se a Drummond como "poeta e funcionário público, autor da teoria segundo a qual o intelectual trai por vocação" (PERALVA, 1951 apud ANTELO, 1984, p. 277).
} 
do acervo da Biblioteca da Faculdade de Letras da Universidade de Lisboa, cota LB 352 P, ref. ULFL145808.

ANDRADE, Carlos Drummond de. O voo sobre as igrejas. Atlântico: Revista Luso-Brasileira, Lisboa, n. 1, 23 maio 1942a.

ANDRADE, Carlos Drummond de. Versos à boca da noite. Atlântico: Revista Luso-Brasileira, Lisboa, n. 2, 31 out. 1942b.

ANDRADE, Carlos Drummond de. Obra completa. 2 ed. Rio de Janeiro: Companhia José Aguilar Editora, 1967.

ANDRADE, Mário de. O gênio e a obra do Aleijadinho. Atlântico: Revista Luso-Brasileira, Lisboa, n. 1, p. 24-31, 23 maio 1942.

ANDRADE, Mário de. Vida literária. São Paulo: Edusp; Hucitec, 1993.

ATLÂNTICO: Revista Luso-brasileira. Lisboa: Secretariado da Propaganda Nacional; Rio de Janeiro: Departamento de Imprensa e Propaganda, 19421950.

BANDEIRA, Manuel. Crônicas da província do Brasil. Rio de Janeiro: Civilização Brasileira, 1937.

BANDEIRA, Manuel. Crônicas inéditas II. Organização, posfácio e notas de Júlio Castañon Guimarães. São Paulo: Cosac Naify, 2009.

BORTOLOTI, Marcelo (org.). Carlos Drummond de Andrade e Ribeiro Couto: correspondência. São Paulo: Editora Unesp, 2019.

CAMILO, Vagner. Uma poética da indecisão: Brejo das Almas. Novos Estudos Cebrap, São Paulo, n. 57, p. 37-58, jul. 2000.

CAMILO, Vagner. A cartografia lírico-social de Sentimento do mundo. Revista USP, São Paulo, n. 53, p. 64-75, mar.-mai. 2002. DOI: https://doi. org/10.11606/issn.2316-9036.v0i53p64-75.

CANDIDO, Antonio. Vários escritos. São Paulo: Duas Cidades, 1977.

CANDIDO, Antonio. Drummond prosador, fazia frio em São Paulo. In: . Recortes. São Paulo: Companhia das Letras, 1993.

CANDIDO, Antonio. Prefácio. In: MICELI, Sérgio. Intelectuais à brasileira . São Paulo: Companhia das Letras, 2001. p. 71-75.

COLABORADORES deste número. Atlântico: Revista Luso-Brasileira, Lisboa, n. 1, p. 176-179, 23 maio 1942. 
CONFERÊNCIAS. Correio da Manhã, Rio de Janeiro, 14 ago. 1945, p. 11.

DUTRA, Eliana Freitas. Laços fraternos: a construção imaginária de uma comunidade cultural luso-brasileira no Almanaque de Lembranças. Revista do Arquivo Público Mineiro, Belo Horizonte, v. 1, 2005.

EMBAIXADOR das letras portuguesas. A Noite, Rio de Janeiro, 7 jul. 1945, p. 3 .

FERRO, António. Algumas palavras. Atlântico: Revista Luso-Brasileira, Lisboa, n. 1, 23 mai. 1942.

FERRO, António. Estados Unidos da saudade. Lisboa: Edições SNI, 1949.

FREYRE, Gilberto. Um livro do senhor Osório de Oliveira. Correio da Manhã, Rio de Janeiro, 20 nov. 1940, p. 2.

GLEDSON, John. Poesia e poética de Carlos Drummond de Andrade. São Paulo: Duas Cidades, 1981.

GUIMARÃES, Lúcia Maria Paschoal. Nos subterrâneos das relações luso-brasileiras, dois estudos de caso: o sucesso da (re)inauguração da sala do Brasil, na Universidade de Coimbra (1937) e o fracasso do Congresso Luso-Brasileiro de História (1940). In:___ (org.). Afinidades atlânticas: impasses, quimeras e confluências nas relações luso-brasileiras. Rio de Janeiro: Quartet, 2009.

MINISTÉRIO DA CULTURA. Fundação Casa de Rui Barbosa. ArquivoMuseu de Literatura Brasileira. Inventário do arquivo Carlos Drummond de Andrade. Rio de Janeiro: Edições Casa de Rui Barbosa, 1998.

MOREIRA, Luiza Franco. Meninos, poetas e heróis: aspectos de Cassiano Ricardo do modernismo ao Estado Novo. São Paulo: Edusp, 2001.

MOURA, Murilo Marcondes de. Desejo de transformação. In: ANDRADE, Carlos Drummond de. Sentimento do mundo. São Paulo: Companhia das Letras, 2012.

OLIVEIRA, José Osório de. Adeus à literatura brasileira. Diário de Lisboa, Lisboa, 16 jun. 1940a, p. 3.

OLIVEIRA, José Osório de. [Correspondência]. Destinatário: Carlos Drummond de Andrade. Lisboa, 11 nov. 1940b, 2p. Documento pertencente ao Arquivo de Carlos Drummond de Andrade, da Casa de Rui Barbosa (código de referência: CDA-CP-1279-1-2). 
OLIVEIRA, José Osório de. [Correspondência]. Destinatário: Carlos Drummond de Andrade. Lisboa, 2 dez. 1940c, 2p. Documento pertencente ao Arquivo de Carlos Drummond de Andrade, da Casa de Rui Barbosa (código de referência: CDA-CP-1279-3-4).

OLIVEIRA, José Osório de. Um estudo sobre Carlos Drummond de Andrade. Ultramar, Lisboa, n. 1, fev. 1941a.

OLIVEIRA, José Osório de. [Correspondência]. Destinatário: Carlos Drummond de Andrade. Lisboa, 8 out. 1941b, 1p. Documento pertencente ao Arquivo de Carlos Drummond de Andrade, da Casa de Rui Barbosa (código de referência: CDA-CP-1279-5).

OLIVEIRA, José Osório de. Um estudo sobre Carlos Drummond de Andrade. A Manhã, Rio de Janeiro, n. 16, p. 340-341, 30 nov. 1941c [Autores e Livros].

OLIVEIRA, José Osório de. Um poeta brasileiro (exemplo de crítica apologética). In: . Enquanto é possivivel. Lisboa: Edições "Universo", 1942a, p. 141-150.

OLIVEIRA, José Osório de. Notas - O primeiro artigo. Atlântico: Revista Luso-Brasileira, Lisboa, n. 1, p. 170-175, 23 maio 1942b.

OLIVEIRA, José Osório de. [Correspondência]. Destinatário: Mário de Andrade. Lisboa, out. 1943. In: SARAIVA, Arnaldo. Modernismo brasileiro e modernismo português. Campinas, SP: Editora da Unicamp, 2004. p. 457458.

OLIVEIRA, José Osório de. Notas. Atlântico: Revista Luso-Brasileira, Lisboa, n. 6, p. 198-199, 21 abr. 1945a.

OLIVEIRA, José Osório de. Mário de Andrade. Atlântico: Revista LusoBrasileira, Lisboa, n. 6, p. 183-186, 21 abr. 1945b.

OLIVEIRA, José Osório de. Na minha qualidade de luso-brasileiro (elementos para a história das relações literárias entre Brasil e Portugal). Lisboa: [s. ed.], 1948.

OLIVEIRA, José Osório de. Carta a Carlos Drummond de Andrade. Lisboa, 16 fev. 1957, 1p. Documento pertencente ao Arquivo de Carlos Drummond de Andrade, da Casa de Rui Barbosa (código de referência: CDA-CP-1279-9). 
OLIVEIRA, José Osório de (org.). Prosas brasileiras. Lisboa: Bertrand, 1949 ?.

OLIVEIRA, José Osório de (org.). Líricas brasileiras - Séculos XIX e XX. Lisboa: Portugália Editora, 1954.

PERALVA, Oswaldo. "Intelectuais que traíram o povo". Para Todos, Rio de Janeiro, n. 7, p. 10-11, mar. 1951 apud ANTELO, Raul. Literatura em revista. São Paulo: Ática, 1984, p. 276-277 (Ensaios; 105).

PY, Fernando. Bibliografia comentada de Carlos Drummond de Andrade (1918-1930). Rio de Janeiro: José Olympio, Fundação Casa de Rui Barbosa; Brasília: INL, 1980.

REGO, José Lins do. Atlântico. A Manhã, Rio de Janeiro, 12 ago. 1942, p. 4.

SALLA, Thiago Mio. A divulgação de Graciliano Ramos em Portugal nas páginas da revista Atlântico: suporte e atenuação do sentido. Via Atlântica, São Paulo, n. 31, p. 59-78, jun. 2017. DOI: https://doi.org/10.11606/ va.v0i31.131891.

SANT'ANNA, Affonso Romano de. Drummond, o gauche no tempo. Rio de Janeiro: Lia; INL, 1972.

SARAIVA, Arnaldo. Modernismo brasileiro e modernismo português. Campinas, SP: Editora da Unicamp, 2004.

SERRANO, Gisella de Amorim. Caravelas de papel: a política editorial do Acordo Cultural de 1941 e o pan-lusitanismo (1941-1949). 2009. $316 f$. Tese (Doutorado em História) - Universidade Federal de Minas Gerais, Belo Horizonte, 2009.

VIAJANTES, Correio da Manhã, Rio de Janeiro, 6 jul. 1945, p. 9.

Recebido em: 26 de fevereiro de 2020.

Aprovado em: 23 de julho de 2020. 